\title{
Correction to: Interest in Research Participation Among Caregivers of Children with Neurodevelopmental Disorders
}

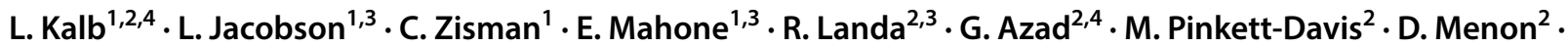 \\ V. Singh ${ }^{2} \cdot$ A. Zabel ${ }^{1,3} \cdot$ A. Pritchard ${ }^{1,3}$
}

Published online: 29 August 2019

○) Springer Science+Business Media, LLC, part of Springer Nature 2019

\section{Correction to: \\ Journal of Autism and Developmental Disorders (2019) 49:3786-3797 \\ https://doi.org/10.1007/s10803-019-04088-9}

During the publication process, an author "M. PinkettDavis", who helped conceptualize and revise this study was accidentally excluded from the authorship list.

The revised author group is now:

Kalb, L., Jacobson, L., Zisman, C., Mahone, E., Landa, R., Azad, G., Pinkett-Davis, M., Menon, D., Singh, V., Zabel, A., \& Pritchard, A.

Please use this authorship list when citing this manuscript.
Publisher's Note Springer Nature remains neutral with regard to jurisdictional claims in published maps and institutional affiliations.

The original article can be found online at https://doi.org/10.1007/ s10803-019-04088-9.

L. Kalb

kalb@kennedykrieger.org

1 Department of Neuropsychology, Kennedy Krieger Institute, 1750 E. Fairmount Ave, Baltimore, MD 21231, USA

2 Center for Autism and Related Disorders, Kennedy Krieger Institute, Creamer Family Building, 3901 Greenspring Avenue, Baltimore, MD 21211, USA

3 Department of Psychiatry and Behavioral Sciences, Johns Hopkins School of Medicine, 707 N. Broadway, Baltimore, MD 21205, USA

4 Department of Mental Health, Johns Hopkins School of Public Health, 615 N. Wolfe St, Baltimore, MD 21205, USA 